\title{
Roteirização e Turismo Cultural: percepção de empreendedores e turistas sobre o Roteiro Caminhos do Frio em Areia, Paraíba
}

\section{Routing and Cultural Tourism: entrepreneurs and tourists' perceptions about the "Caminhos do Frio" Cultural Route in Areia, Paraíba (Brazil)}

\author{
Priscila Fernandes Carvalho de Melo ${ }^{1}$ \\ Adriana Brambilla ${ }^{2}$
}

\begin{abstract}
Resumo - Os roteiros turísticos podem ser um importante instrumento para estimular a interação entre turista população local com o objetivo de fortalecer a identidade cultural. $\mathrm{Na}$ Paraíba, foi proposta a criação de um roteiro turístico de forma a fomentar a interiorização do turismo, que normalmente se concentra no litoral paraibano. O Roteiro Cultural Caminhos do Frio abrange nove municípios que se localizam no brejo paraibano e que, de acordo com os responsáveis pelo roteiro têm como foco o turismo cultural. Neste sentido, o presente artigo, buscou responder ao seguinte questionamento: os empreendedores dos meios de hospedagem e turistas percebem que o Roteiro Cultural Caminhos do Frio está contribuindo para o fortalecimento da identidade cultural da população local do município de Areia/PB? Desta forma, adotou-se a pesquisa bibliográfica, documental e descritiva com abordagem quantitativa $\mathrm{e}$ qualitativa contemplando dois grupos: os meios de hospedagem e os turistas. A partir dos resultados obtidos, verificou-se que os meios de hospedagem percebem $o$ fortalecimento da identidade cultural da população local uma vez que a mesma participa ativamente das atividades desse roteiro com o intuito de demonstrar aos turistas a cultura, a gastronomia, a música e o artesanato, assim como aumenta a divulgação da cidade. Porém, apesar de reconhecer que este roteiro possibilita a demonstração das manifestações culturais fortalecendo a identidade cultural, os turistas consideram que o contato com a população local, muitas vezes, é superficial, impossibilitando que possam conhecer mais sobre a história e a cultura local.
\end{abstract}

Palavras-chave: Turismo Cultural. Roteirização. Caminhos do Frio.

\footnotetext{
1 Graduação em Ciências Contábeis pela Universidade Federal da Paraíba (UFPB). Mestranda em Hotelaria e Turismo pela Universidade Federal de Pernambuco (UFPE). Graduanda em Hotelaria pela UFPB. Pesquisadora do Grupo de Cultura e Estudos em Turismo (GCET). E-mail: priscillajp@hotmail.com

${ }^{2}$ Doutorado em Estudos Culturais pela Universidade de Aveiro, Portugal. Mestrado em Administração pela Universidade Federal da Paraíba (UFPB). Graduação em Administração pela Fundação Armando Álvares Penteado (FAAP-SP). Docente do Departamento de Turismo e Hotelaria da UFPB. Líder do Grupo de Cultura e Estudos em Turismo (GCET). E-mail: adrianabrambillaa@yahoo.com.br
} 


\begin{abstract}
Tourist Routes can be an important tool to bring people together and stimulate the interaction of tourists and local population in order to strengthen the cultural identity. In Paraíba State (Brazil), it was proposed the creation of a tourist itinerary in order to promote the interiorization of the tourism in the state, which is usually concentrated on the coast. The "Caminhos do Frio" Cultural Tour covers nine cities that are located in the swamp region of Paraíba state that, according to those responsible for the route, focus on cultural tourism. In this sense, this article sought to answer the following question: lodging entrepreneurs and tourists realize that the "Caminhos do Frio" Cultural Route is contributing to the strengthening of the local population cultural identity in Areia, Paraíba? In this way, bibliographic, documentary and descriptive research were used with quantitative and qualitative, approaching with two groups: lodging entrepreneurs and tourists. From the results obtained, it was found that the means of accommodation realize the strengthening of the local population cultural identity since the population actively participates in the activities of this itinerary in order to demonstrate to the tourists the culture, gastronomy, music and handicrafts, as well as increasing the publicity of the city. However, despite recognizing that this itinerary allows the demonstration of cultural manifestations, strengthening the cultural identity, the tourists consider that contact with the local population is often superficial, making it impossible for these tourists to learn more about the local history and culture.
\end{abstract}

Keywords: Cultural Tourism. Routing. Caminhos do Frio. 


\section{INTRODUÇÃO}

A complexidade da atividade turística exige uma análise não apenas como um tipo de negócio, mas como um complexo cenário cultural, moldado por representações de lugares, povos e culturas. No entanto, o turismo se apresenta como uma atividade promissora para o desenvolvimento das localidades na qual seu desempenho está diretamente ligado à criação de empregos, melhorias na infraestrutura, na distribuição de renda e na melhoria da qualidade de vida. Porém, para que o turismo possa dar um retorno para a comunidade e para o trade turístico (hotelaria, bares e restaurantes) é necessário que o mesmo seja bem elaborado e planejado. Assim, os roteiros turísticos auxiliam na organização e expansão de produtos turísticos, uma vez que devem ser elaborados pensando na logística do espaço físico, do tempo e da comodidade dos turistas (BAHL, 2004).

Diante deste contexto, os roteiros turísticos representam os atrativos de uma localidade, os quais podem ser culturais, históricos, de aventura entre outros. O roteiro cultural Caminhos do Frio, que foi idealizado pela prefeitura da cidade de Areia, no Estado da Paraíba, em 2005, surge com o objetivo de somar suas potencialidades com as dos municípios da região para valorizar e fortalecer a cultura do Brejo Paraibano. Segundo dados do IBGE (2018) a Paraíba é dividida geograficamente em 4 mesorregiões abrangendo 23 microrregiões. O município de Areia/PB encontra-se na mesorregião do Agreste Paraibano e na microrregião do Brejo Paraibano.

O Brejo Paraibano conta com 32 municípios e nove fazem parte do roteiro cultural Caminhos do Frio, a saber: Areia, Pilões, Remígio, Solânea, Serraria, Bananeiras, Matinhas, Alagoa Nova e Alagoa Grande. Dentre eles, para efeitos deste estudo destaca-se o município de Areia que tem como tema "Frio, Cachaça e Arte".

Areia é um dos municípios mais importantes do Brejo Paraibano, sendo o único município do roteiro cultural Caminhos do Frio com conjunto urbano tombado pelo Iphan (Instituto do Patrimônio Histórico e Artístico Nacional) devido ao seu valor histórico, urbanístico, paisagístico e arquitetônico (IPHAN, 2014). Com uma população estimada de 22.000 habitantes (IBGE, 2018), a cidade, também conhecida como a "Suíça Paraibana" (PARAÍBA, 2008). Ela está a 124 km da capital, João Pessoa, oferecendo aos turistas uma riqueza cultural, pois foi na cidade que nasceu Pedro 
Américo, pintor reconhecido por produzir o quadro do "Grito do Ipiranga", e foi palco da campanha promovida por abolicionistas, sendo a primeira cidade do Brasil a abolir a escravidão, embora os negros fizessem parte da estrutura econômica da região, para o cultivo de cana-de-açúcar da zona rural no final do século XIX (ANDRADE, 1997). Além disso, a cidade possui mais de 20 engenhos históricos, disponíveis à visitação com fabricação de aguardente, mel e rapadura, e ainda, museus, igrejas, riachos e cachoeiras, trilhas e uma natureza ainda preservada em grande parte (FCJA, 2018).

Para o desenvolvimento desse roteiro, os municípios contam com o apoio do Fórum de Desenvolvimento Turístico Sustentável do Brejo Paraibano e do Governo do Estado, por meio da Empresa Paraibana de Turismo (PBTur), Sebrae (Serviço Brasileiro de Apoio às Micro e Pequenas Empresas), Atura (Associação Turística Cultural e Rural de Areia) e prefeituras dos municípios que integram o roteiro cultural Caminhos do Frio (CRIATIVA, 2018).

O "Caminhos do Frio", principal evento cultural da Paraíba, foi desenvolvido com o intuito de divulgar o cenário cultural, gastronômico, musical e arquitetônico desses municípios disseminando assim a cultura do brejo paraibano. Desta forma, este roteiro acontece de julho a setembro, período em que os turistas podem encontrar um clima mais agradável com temperaturas de até 12 graus (RUSSO, 2017), consolidando a região como produto turístico e gerando renda para os municípios.

Desta forma, os agentes que apoiam este roteiro têm por objetivo fomentar a identidade cultural local e o crescimento econômico através da divulgação em meios de comunicação e incentivando os moradores locais a difundir sua cultura, a gastronomia, música, artesanato e arquitetura durante o Caminhos do Frio. Portanto, a PBTUR e o SEBRAE são responsáveis pelos Fampress, ou seja, por levar representantes do meio de comunicação e realizar a divulgação e a prefeitura de Areia em conjunto com a ATURA são responsáveis pelo apoio cultural.

O apoio da ATURA tem grande importância na organização do roteiro no município de Areia/PB, demonstrando que a associação tem iniciativa e funciona como incentivadora das atividades locais, dando ênfase no fortalecimento da cultura gerando renda para o município. Porém a PBTUR e o SEBRAE também auxiliam nessa organização. 
A pesquisa limitou-se ao município de Areia, pois segundo o Ministério do Turismo (BRASIL, 2018), este município é um dos 3.285 municípios considerados locais de interesse turístico no Mapa do Turismo Brasileiro (MAPA), um instrumento de políticas públicas que auxilia no desenvolvimento do turismo regional por meio de ações como infraestrutura turística, qualificação profissional e promoção do destino turístico, considerando as características, demandas e capacidade de cada destino (BRASIL, 2018).

Observando o trade turístico e, de acordo com as necessidades de atendimento dos desejos e expectativas dos turistas, os quais, não buscam mais apenas obter um serviço ou produto, mas sim, novas experiências e sensações oriundas dos serviços e/ou produtos que integram a comunidade local, emerge o questionamento: empreendedores dos meios de hospedagem e turistas percebem que o Roteiro Cultural Caminhos do Frio, está contribuindo para o fortalecimento da identidade cultural da população local do município de Areia/PB?

Desta forma o estudo desenvolvido sobre o roteiro cultural Caminhos do Frio é importante para verificar se as ações desenvolvidas estão valorizando a população local, a cultura e os costumes.

\section{REFERENCIAL TEÓRICO}

Com o avanço da tecnologia e a crescente transformação dos serviços turísticos, o turista não se satisfaz apenas com o serviço e produto oferecido, há a necessidade de superar as expectativas, de surpreender e criar novas experiências, integrando a experiência turística com a experiência cultural (FORNÉ; JIMÉNEZ, 2015).

Todavia, o turismo por ser um mercado hegemônico, ou seja, desigual, impulsiona os empresários a delimitarem seu público alvo para atender as necessidades, desejos e preferências do novo padrão de consumo, consentindo assim, o surgimento de segmentos de mercado que agrupam características homogêneas de grupos de consumo (LAS CASAS, 2015). Porém, quando um segmento se torna mais específico e estrito, surge um sub segmento ou nicho de mercado na qual buscam benefícios distintos de grupos específicos (KOTLER e KELLER, 2012). Como resultado dessa divisão, o surgimento de tipos de turismo que vão se adequando não só à demanda, mas também 
às características dos núcleos receptores, permite a expansão de novas atividades para outras regiões que não são representados pelos grandes centros urbanos ou nos locais de sol e mar (BRAMBILLA; VANZELLA; BAPTISTA, 2014).

Entre estes segmentos, está o turismo motivado pela cultura, denominado de turismo cultural e definido por Timothy e Boyd (2006) como o interesse do turista em se deslocar de seu lugar de residência para assistir e participar de atividades culturais sejam elas visitas a museus, manifestações artísticas e culturais, representações, entre outras.

Logo, as localidades investem na pluriatividade, ou seja, na realização de outras atividades com o objetivo reestabelecer a economia e sustentar as ações já existentes (RIBEIRO; MONDO, 2019), ou seja, de diversificar os negócios. Desta forma, para que uma localidade se torne competitiva em meio ao interesse econômico das cidades (VIANA, 2019) surge a necessidade de integrá-las a roteiros turísticos (DANTAS; MELO, 2011), uma vez que esses roteiros turísticos, quando desenvolvidos em um espaço rural apresentando características culturais pode impulsionar o desenvolvimento de outras atividades e novas fontes de renda (BRAMBATTI, 2019).

Segundo o Ministério do Turismo (BRASIL, 2007, p. 13), entende-se por roteiros turísticos como o "itinerário caracterizado por um ou mais elementos que lhe conferem identidade. É definido e estruturado para fins de planejamento, gestão, promoção e comercialização turística". Na academia e no mercado, termos sinônimos são associados a roteiro turístico, como: rota turística, roteirização, itinerário turístico, pacote turístico (DANTAS; MELO, 2011) como demonstra a pesquisa realizada por Gonçalves e Ribeiro (2016) sobre a definição acadêmica entre rota e roteiro. Porém para fins desse estudo, será considerado o termo roteiro turístico adotado por Tavares (2002), Bahl (2004) e Ministério do Turismo (2007).

Os roteiros turísticos são utilizados como instrumento para divulgar as potencialidades de uma região a partir dos atrativos que os representa, promovendo suas especificidades (DANTAS; MELO, 2011) sendo importante para a diversificação turística (BRASIL, 2007). Contudo, Tavares (2002) já discutia a importância dos roteiros turísticos, acrescentando que os mesmos não devem ser apenas inseridos como uma sequência de atrativos, mas sim, como uma forma do turista ter a possibilidade de conhecer a realidade daquela localidade, a cultura e o povo. Assim, os roteiros turísticos 
geralmente são planejados contendo um tema que valorize o ambiente natural e cultural de uma região, cruzando informações e atrativos turísticos para que os mesmos possam ser divulgados como produtos turísticos (CISNE; GASTAL, 2009) contribuindo para o desenvolvimento da localidade.

Portanto, os roteiros turísticos são utilizados como indutores da atividade turística (ANDRADE, 2013) fazendo com que os turistas tenham experiências diversas com o lugar, a cultura e a população (PIRES, 2017). Porém, deve-se considerar que os roteiros turísticos são também instrumento de inclusão social a partir do caráter participativo da população local, na qual busca valorizar a cultura e o ambiente (ALMEIDA, 2006).

Os roteiros turísticos associados à cultura, implicam na troca de experiências entre o visitante e a população receptora, tornando-se importante ressaltar o termo "vivência" (BRAMBILLA; VANZELLA; BAPTISTA, 2014). Caracteriza-se, também, pela motivação do turista em conhecer regiões onde o seu alicerce está baseado na história de um determinado povo, nas suas tradições e nas suas manifestações culturais, históricas e religiosas (MOLETTA, 1998). Smith (2003), explica que o turismo cultural não se relaciona apenas ao passado, mas também ao presente, isto é, baseia-se "tanto na história de um local e do seu povo, como na sua vida contemporânea", denominando o modo de vida das pessoas de uma região.

No intuito de evitar a padronização dos atrativos culturais, exige-se uma aproximação dos setores turísticos e culturais para que possam criar novos produtos culturais e que sejam inovações para o turismo, e ao mesmo tempo, encontrem formas inovadoras do turismo apoiar a cultura (BRAMBILLA; VANZELLA; BAPTISTA, 2014). Os autores asseveram que, quanto mais a comunidade participa do processo de planejamento, mais enriquecedor será o conhecimento adquirido pelo turista durante a visitação. Dessa forma ele se envolve na realidade daquele lugar e procura conhecer a história e os símbolos expressos nos bens materiais e imateriais, e população local tem a possibilidade de demonstrar sua cultura, fortalecendo-a. Por fim, os autores afirmam que, turismo cultural é o acesso ao patrimônio cultural, ou seja, à história, à cultura e ao modo de viver de uma comunidade.

O eixo cultural considera que o ato de receber, hospedar, alimentar e entreter está presente na história da população. Neste caso pode-se considerar que a 
hospitalidade é uma das características presentes na cultura. Camargo (2015) considera que todas as culturas possuem princípios e leis não escritas da hospitalidade, herdadas por gerações anteriores que regulamentam o relacionamento humano no ambiente familiar ou fora dele. Assim, a identidade cultural de uma população está associada a herança não material e material herdada por gerações anteriores, e sua grande dificuldade é manter-se em meio a tecnologia e globalização sem por em risco sua identidade cultural e criar novas dependências e transformações (COLAÇO e SPAREMBERGER, 2010).

Nesse contexto, entende-se por cultura o conjunto de características que define cada pessoa ou grupo de pessoas, como comportamento, crenças, músicas, modo de vestir, manifestações artísticas e outros representando os sentimentos de um povo (MARTINS, 2007). Segundo Pezzi e Santos (2012), “os turistas buscam vivenciar acontecimentos únicos e marcantes". Percebe-se a formação de um novo perfil do turista mais interessado em conhecer outras realidades, em participar e conhecer em profundidade pessoas e localidades. Assim, compreender a cultura de um determinado local representa a integração do turista com a população local, pois a cultura é dinâmica e sofre influências locais e globais.

\section{PROCEDIMENTOS METODOLÓGICOS}

Este estudo caracteriza-se por ser uma pesquisa bibliográfica, documental e descritiva com abordagem qualitativa. Inicialmente foi realizado um levantamento bibliográfico por meio das plataformas de busca como Periódicos Capes, Scholar Google, livros e revistas da área do turismo que abordassem os roteiros e rotas culturais, turismo e cultura. A revisão de literatura auxilia o pesquisador a ampliar e construir o conhecimento científico a partir de um aprofundamento teórico sobre um tema específico (RODGERS; KNAFL, 2000), uma vez que é a partir desse processo que surgem novas teorias, possíveis lacunas, possibilidade de análise crítica (VOSGERAU; ROMANOWSKI, 2014) e consequentemente pesquisas futuras (BOTELHO; CUNHA; MACEDO, 2011). Por sua vez, a pesquisa descritiva caracteriza-se pela intenção de descrever o objeto estudado (MALHOTRA, 2011), não havendo a pretensão de se testar hipóteses. 
O estudo tem uma abordagem quantitativa e qualitativa e utilizou como estratégia de pesquisa o survey online (LEEUW, DILLMAN e HOX, 2007), através do questionário como instrumento de coleta de dados. Para atender ao objetivo da pesquisa foram elaborados 2 questionários: para os turistas, foi utilizado o questionário estruturado contendo uma pergunta subjetiva e onze objetivas. Assim, a população do estudo foi caracterizada por brasileiros que já haviam visitado o destino turístico Areia, PB. Deste modo, o estudo foi uma amostragem não-probabilística, uma vez que não se conhece o tamanho da população e os indivíduos foram selecionados por critérios dos pesquisadores (MARCONI; LAKATOS, 1996 e ARIBONI; PERITO, 2004).

Dentre os tipos de amostragem não-probabilística, optou-se pela amostragem por conveniência (MALHOTRA, 2011) na qual o pesquisador seleciona os elementos a que tem acesso, considerando que estes possam representar um universo (LWANGA; LEMESHOW, 1991). Assim, os pesquisadores selecionaram os participantes com base no seguinte critério: que já houvesse visitado o município no período do roteiro cultural e com disponibilidade de participar da pesquisa. Para aumentar o alcance da amostra, a técnica escolhida foi a snowball, que caracteriza-se pela divulgação da pesquisa por meio de indicações entre indivíduos, possibilitando o compartilhamento em grupos sociais diversos (ATKINSON; FLINT, 2001).

Os questionários ficaram on-line no Google Forms para os possíveis respondentes no período de abril a maio de 2019. Desta forma, obteve-se a resposta de 69 turistas, sendo que 5 desses não responderam por completo o questionário, sendo necessário descartá-los. Assim, foram considerados para a análise 64 respondentes. Para o segundo questionário, a pesquisa abordou 4 meios de hospedagem. Para a seleção dos meios de hospedagem, foi analisado os que estariam classificados como pousada, hotel, hotel fazenda e hotel histórico, segundo o sistema brasileiro de classificação SBCLASS. Para manter a confiabilidade da pesquisa, foi observado o cadastro dos meios de hospedagem no CADASTUR - Cadastro de pessoas físicas e jurídicas que atuam no setor do turismo (BRASIL, 2020).

O questionário direcionado aos meios de hospedagem buscou analisar se os empreendedores conseguiam perceber o fortalecimento da cultura, gastronomia, maior participação da população local a partir das atividades econômicas desenvolvidas pelos mesmos e se o roteiro trazia benefícios também para os empreendimentos hoteleiros já 
existentes no município. Por fim, foi necessário obter as respostas dos turistas para atender ao objetivo desta pesquisa, na qual busca verificar, também, se os turistas percebem o fortalecimento da identidade cultural no município de Areia/PB a partir de uma maior participação da população local através de manifestações culturais, gastronomia, arte, música e artesanato no roteiro cultural Caminhos do Frio.

As análises das respostas, nas questões subjetivas, proporcionaram a compreensão da opinião das pessoas que participaram da pesquisa através da análise qualitativa e, as questões objetivas, permitiram uma abordagem quantitativa com a tabulação e análise dos dados através de gráficos para explicar o fenômeno (PRODANOV; FREITAS, 2013).

\section{RESULTADOS}

Os dados analisados foram obtidos a partir de questionário online aplicado no período de abril a maio de 2019. Durante a coleta de dados, observou-se que apenas 4 meios de hospedagem, dentre os seis que estão no município, responderam ao questionário, sendo os demais ostensivos a participação da pesquisa. Em contrapartida todos os agentes responsáveis por promover o roteiro cultural Caminhos do Frio no município de Areia-PB responderam os questionários. Em relação aos turistas, dos 64 questionários válidos, observou-se que 52 são do sexo feminino e 12 do sexo masculino. A faixa etária variou entre 19 e 66 anos de idade, conforme gráfico 1.

\section{GRÁFICO 1: PERFIL DOS RESPONDENTES.}

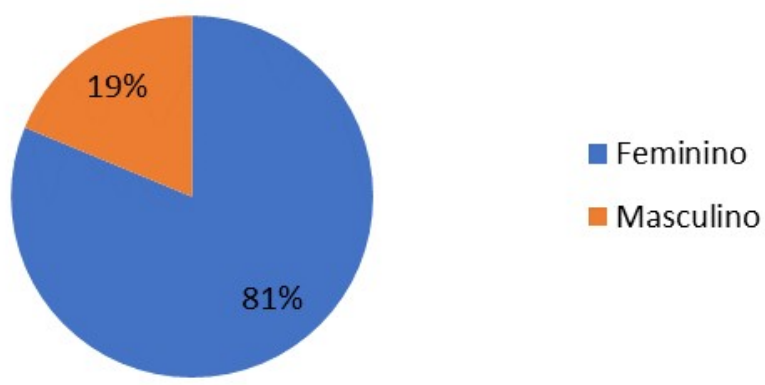

FONTE: Dados da pesquisa, 2019

Para melhor compreensão dos resultados, os autores dividiram essa seção em duas partes: meios de hospedagem e turistas. 


\subsection{MEIOS DE HOSPEDAGEM}

O questionário aplicado aos meios de hospedagem buscou compreender a visão desses empresários em relação aos benefícios que este roteiro trouxe para o município e consequentemente para o seu empreendimento, uma vez que as ações que acontecem no roteiro envolvem as manifestações culturais, gastronomia, artesanato, música e outras atividades que movimentam a economia local.

Desta forma, foram abordadas perguntas sobre o crescimento do número de turistas, se o roteiro é considerado o maior atrativo da cidade e se houve benefícios para a população local e para os empreendimentos hoteleiros.

Quando questionado se o roteiro é considerado o maior atrativo do município, $50 \%$ dos meios de hospedagem que estão envolvidos no "Caminhos do Frio", consideram esse roteiro como o maior atrativo que movimenta economicamente a região, porém os outros $50 \%$ acreditam que há outros atrativos que movimentam o município (Gráfico 2), como por exemplo, a cachaça, os engenhos e a história local.

\section{GRÁFICO 2: ROTA CULTURAL CAMINHOS DO FRIO COMO PRINCIPAL ATRATIVO}

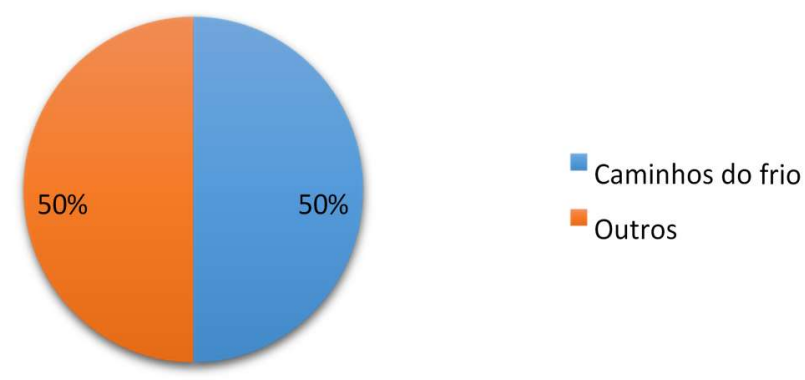

FONTE: Dados da pesquisa, 2019

Todos os entrevistados, representando $100 \%$ das opiniões, responderam "sim" quando questionado se o Caminhos do Frio foi responsável pelo crescimento no fluxo de visitantes, se trouxe benefícios para os empreendimentos e para o município. Demonstrando com isso, a aceitação do roteiro cultural por parte dos empresários.

Quanto à questão sobre os benefícios trazidos pelo roteiro para o município, os itens mais citados foram maior divulgação, com 75\%, e conservação do patrimônio com $25 \%$, conforme Gráfico 3. 
GRÁFICO 3: BENEFÍCIOS PARA O TURISMO, GERADO PELA ROTA CULTURAL
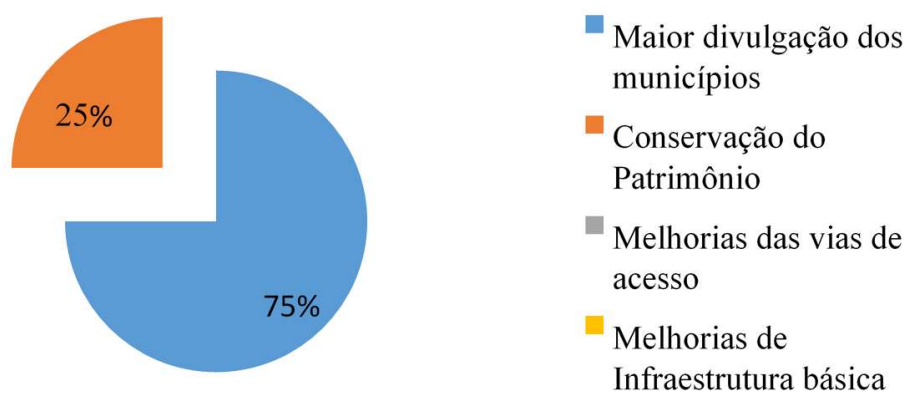

FONTE: Dados da pesquisa, 2019

Consequentemente quando foram perguntados se o "Caminhos do Frio" é uma importante ferramenta de divulgação, todos responderam "sim", afirmando desta forma que a divulgação do roteiro promove o município de Areia.

Já com relação aos benefícios a população local, os empresários expressam na resposta subjetiva que observam o engajamento da população local na participação das atividades culturais que acontecem no roteiro, na qual podem através de sua arte, seja ela abordando a cultura, a gastronomia, a música ou artesanato, expressar suas potencialidades.

$\mathrm{Na}$ última questão, de caráter subjetivo, os empresários dos meios de hospedagem destacaram alguns itens que poderiam ser melhorados para que o roteiro intitulado Caminhos do Frio contribua positivamente para o turismo do município de Areia. Dentre eles estão: ter variedade de atrações nas edições, ou seja, que a cada ano sejam oferecidos novidades para os turistas, para que os mesmos se sintam motivados a participar de todas as edições. Outro ponto também relevante destacado pelos respondentes foi à necessidade do setor público apoiar a oferta de treinamento aos colaboradores dos meios de hospedagem e para todos que fazem parte do roteiro, com o objetivo de receber, acolher e entreter da melhor forma possível, para que o turista tenha suas necessidades e desejos atendidos e muitas vezes superados. 


\subsection{TURISTAS}

O questionário aplicado aos turistas contou com onze perguntas objetivas e uma subjetiva para proporcionar a compreensão do que o turista mais gosta no roteiro cultural "Caminhos de Frio" e para verificar se o mesmo percebe a participação da população local nas atividades, oficinas e shows que são oferecidos durante o roteiro, de forma a demonstrar suas potencialidades.

As duas primeiras perguntas do questionário buscaram analisar quantos turistas conheciam o município de Areia, e quantos haviam visitado o município durante o roteiro cultural Caminhos do Frio. Desta forma, observou-se que 22\% ainda não conheciam o município e $34 \%$ visitaram o município três vezes ou mais, o que demonstra que este destino tem potencial turístico, de acordo com o Gráfico 4.

\section{GRÁFICO 4: VISITAS AO MUNICÍPIO DE AREIA/PB}

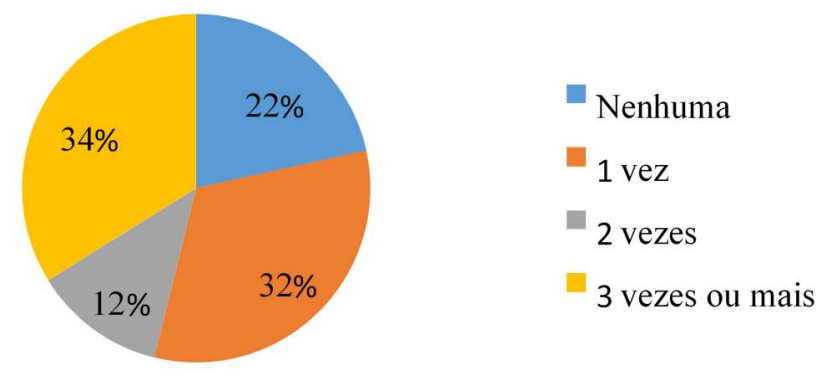

FONTE: Dados da pesquisa, 2019

Quando analisado o número de vezes que esses turistas participaram do roteiro no município de Areia, observou-se que $67 \%$ não conheciam este roteiro. Dentre as outras opções, tivemos os seguintes resultados: $24 \%$ visitaram 1 vez, $3 \%$ visitaram 2 vezes e $6 \%$ tiveram essa experiência 3 vezes ou mais (Gráfico 5). Com isso, observouse que apesar de 78\% das pessoas conhecerem o município de Areia/PB, apenas $33 \%$ participaram do roteiro cultural "Caminhos do Frio" no município. 
GRÁFICO 5: VISITAS À ROTA CULTURAL CAMINHOS DO FRIO - AREIA/PB

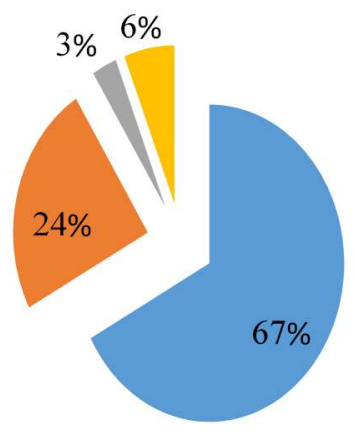

$$
\begin{aligned}
& \text { Nenhuma } \\
& 1 \text { vez } \\
& 2 \text { vezes } \\
& 3 \text { vezes ou mais }
\end{aligned}
$$

FONTE: Dados da pesquisa, 2019

Em seguida os turistas foram questionados a respeito do meio pelo qual tiveram conhecimento sobre o roteiro cultural "Caminhos do Frio", conforme apresentado no Gráfico 6. O maior índice foi relacionado à televisão, 44\% das pessoas, seguido de indicação de amigos, 31\%. As redes sociais foram abordadas apenas por $10 \%$, e sites por $6 \%$. Alguns turistas e visitantes (9\%) marcaram a opção 'outras', porém não especificaram. Apesar dos agentes de apoio realizarem uma divulgação mais voltada às redes sociais, pôde-se observar que o maior meio de divulgação ainda é o televisivo.

\section{GRÁFICO 6: MEIOS DE DIVULGAÇÃO}

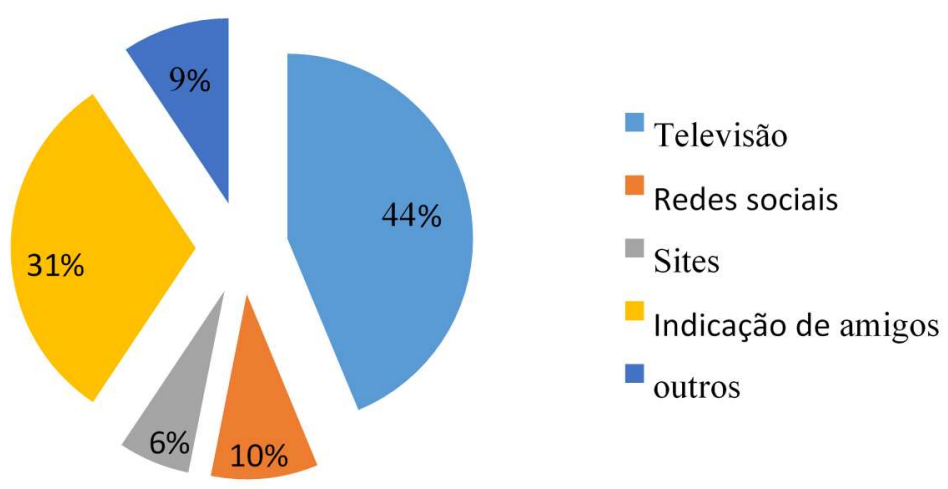

FONTE: Dados da pesquisa, 2019

No que se refere à quantidade de dias e a quantidade de atrativos que o turista participou do Caminhos do Frio, constatou-se que a maioria dos visitantes (12,5\%) fica no município apenas 1 dia dos 7 dias de evento, e participa no máximo de duas atividades que este roteiro proporciona, como demonstram os gráficos 7 e 8 : 


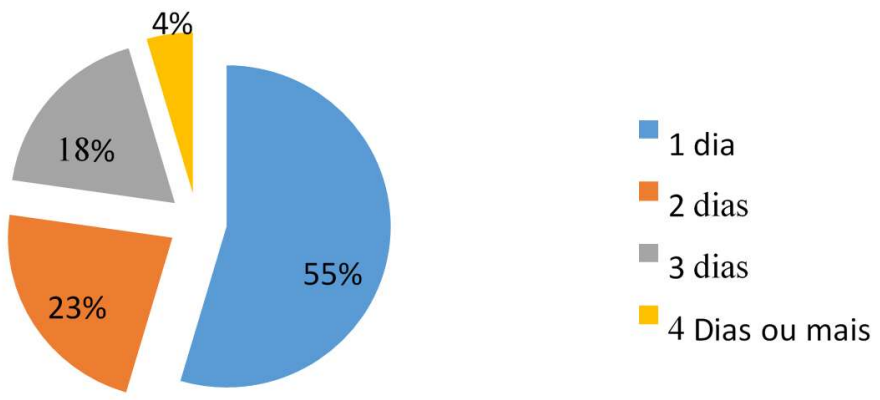

FONTE: Dados da pesquisa, 2019

Devido ao número de dias que a maioria dos turistas ficam no município, a quantidade de atrativos que esse turista pode participar também torna-se reduzido, como pode ser observado no gráfico 8 , na qual a maioria dos turistas participam apenas de $1 \mathrm{a}$ 2 atrativos

\section{GRÁFICO 8: PARTICIPAÇÃO NOS ATRATIVOS}

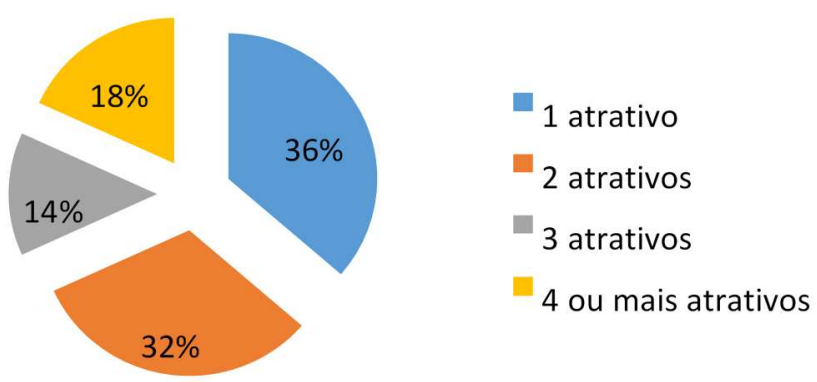

FONTE: Dados da pesquisa, 2019

Analisando os tipos de atrativos que tiveram maior procura por parte dos turistas e visitantes, observou-se que as oficinas gastronômicas foram as mais procuradas (36\%), seguidas das exposições que acontecem nas pousadas, nos casarões históricos e nos restaurantes $(27 \%)$, e os shows que acontecem no turno da noite no palco central (27\%). Por último constam o Sarau poético e as oficinas de artesanato cada um com 5\% das respostas, como mostra o Gráfico 9. 
GRÁFICO 9: TIPOS DE ATRATIVOS

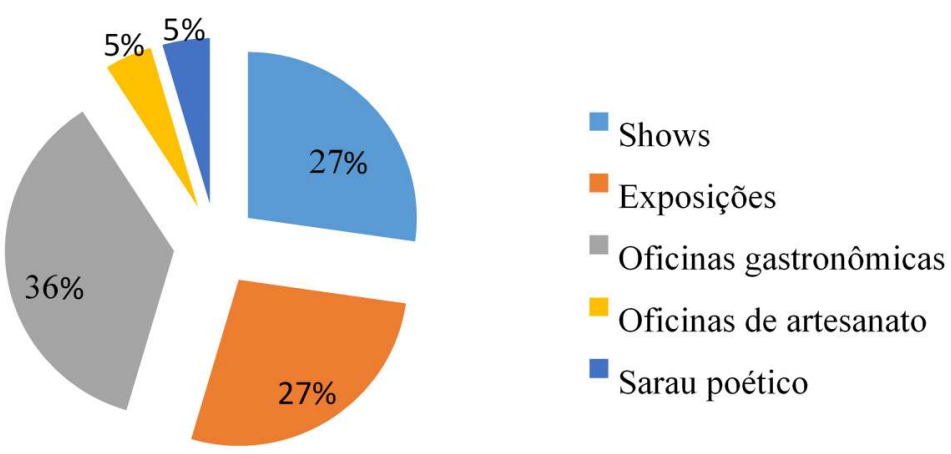

FONTE: Dados da pesquisa, 2019

Assim como os representantes dos empreendimentos hoteleiros, os turistas também foram questionados em perguntas subjetivas se percebem durante o roteiro cultural Caminhos do Frio traços fortes que diferencie a cultura dessa população, seja na música, na gastronomia, nas representações culturais, artesanato e outras atividades. Deste modo os turistas demonstraram ter contato com a população local durante o roteiro, ou seja, há uma interação entre turista e população local durante as atividades que acontecem, seja na comunicação durante uma compra, ou na visualização de uma exposição ou no prazer do paladar de uma gastronomia típica do Brejo Paraibano. Essa interação fazendo com que a população local passe para os turistas um pouco de suas origens, suas histórias, seu modo de viver e suas tradições, ou seja, realiza uma troca de culturas e tornando a experiência do turista única.

Desta forma, os turistas também foram questionados se os mesmos conseguem perceber a participação da população local nas atividades do roteiro cultural, e 91\% pessoas confirmaram essa participação, sendo apenas $9 \%$ que não conseguiram ter essa percepção, conforme apresentado no Gráfico 10.

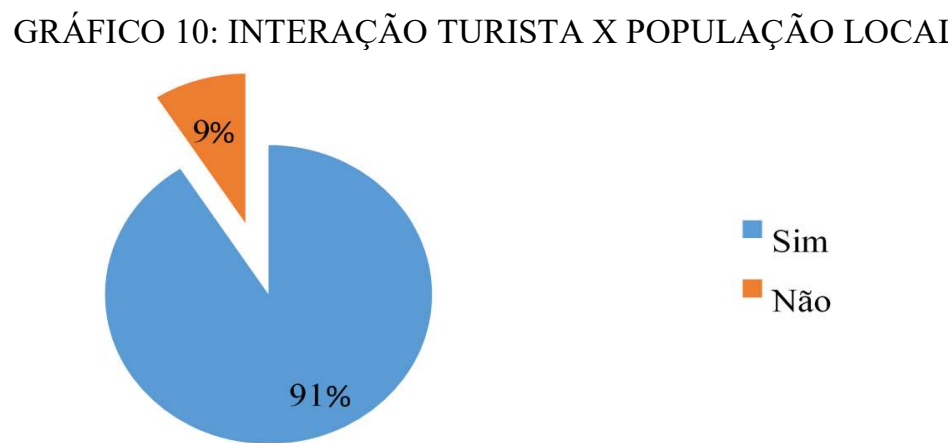

FONTE: Dados da pesquisa, 2019 
Por fim, na pergunta subjetiva, foi solicitado que os turistas expressassem de forma breve o que de fato poderia ser melhorado no roteiro para que os mesmos tivessem um maior contato com a população local, suas histórias e cultura. Deste modo foi sugerido que as atividades poderiam acontecer em ambientes ao ar livre, uma vez que a maioria das atividades, hoje, acontecem em ambientes fechados como os meios de hospedagem, restaurantes e casarões antigos dificultando desta forma a visualização e divulgação das oficinas e exposições. Outro ponto mencionado pelos turistas foi em relação a falta de atrativos ou exposições que demonstrem a história e a cultura local.

\section{CONSIDERAÇÕES FINAIS}

A partir do objetivo de estudo, que buscou verificar se os empreendedores dos meios de hospedagem e turistas percebem que o Roteiro Cultural Caminhos do Frio está contribuindo para o fortalecimento do turismo cultural no município de Areia/PB, podese observar que os agentes buscam inserir a população local na proposta central do Roteiro Cultural, com o intuito de divulgar o cenário cultural, gastronômico, musical e arquitetônico fortalecendo assim a identidade cultural do município.

Observa-se também que o roteiro Caminhos do Frio no município de Areia/PB auxilia na divulgação do destino, diminuindo assim, a sazonalidade em outros períodos, pois a partir dessa atividade, turistas e visitantes ficam conhecendo o município de Areia/PB por seus outros atrativos, como a cachaça e os engenhos. Os agentes de apoio, principalmente a ATURA, vêm trabalhando e estimulando a população local a participar do roteiro, demonstrando para turistas, suas potencialidades, cultura e costumes a fim de fortalecer a identidade cultural da população local.

Contudo, com base nos resultados obtidos observa-se também que há uma necessidade de ampliar a divulgação deste roteiro uma vez que os meios de hospedagem $(50 \%)$ consideram a rota cultural como um dos maiores atrativos da região com contribuições importantes no aumento da demanda do turismo no município e no fortalecimento da identidade cultural. Já os turistas que responderam ao questionário, a maioria já conhece o município de Areia/PB, porém não o conhece durante o período 
que acontece o Caminhos do Frio. Esse resultado demonstra a falta de divulgação deste roteiro para estimular esses turistas a conhecerem os atrativos oferecidos nesse período.

Apesar dos turistas perceberem a cultura e a participação da população local nos atrativos do roteiro e de interagir com os mesmos, há a necessidade de investir nos locais onde essas atividades são realizadas para desta forma ampliar a participação dos turistas nos atrativos oferecidos no roteiro e consequentemente haver um maior contato com a cultura local, gastronomia, artesanato e outros.

O roteiro Caminhos do Frio tem grande potencial a ser desenvolvido por meio dos agentes de apoio e o trade turístico, para atender às necessidades dos visitantes, assim como, para integrar, interagir e estimular a participação da população local com o objetivo de fortalecer a identidade cultural.

Esse estudo, portanto, tem como implicações teóricas promover a discussão sobre as questões que envolvem a roteirização e fortalecimento do turismo cultural, por meio do caso do Roteiro Caminhos do Frio, no município de Areia, PB. Em termos práticos, o estudo tem como contribuição promover um alerta junto ao trade turístico sobre a importância da inclusão da população local a partir da valorização da identidade cultural local, nos eventos que envolvem o município e assim contribuir para que medidas sejam adotadas. Desta forma, essa pesquisa pode ser replicada em todos os municípios que fazem parte da Rota Cultural Caminhos do Frio.

Contudo, houve algumas limitações com relação ao número de meios de hospedagem que responderam ao questionário on-line. Apenas dois estavam cadastrados no CADASTUR, dificultando encontrar meios de hospedagem que pudessem participar da pesquisa. Desta forma, foram utilizados outros meios de busca como plataformas online para identificar os que estavam inseridos no município de Areia/PB. Apesar dessa busca, alguns meios de hospedagem não se disponibilizaram a responder.

Nesse contexto, a necessidade de novos estudos e aprofundamento sobre o tema exige que as questões relacionadas à hospitalidade e ao turismo cultural sejam investigadas e aperfeiçoadas, contribuindo desta forma na escolha de estratégias que ampliem o desenvolvimento da economia local e turística no município de Areia. 


\section{REFERÊNCIAS}

ALMEIDA, M. V. Matriz de avaliação do potencial turístico de localidades receptoras. São Paulo. 2006.

ANDRADE, M. C. O Rio Mamamguape. João Pessoa: Universitária UFPB, 1997.

ANDRADE, M. F. D. O tombamento dos bens arquitetônicos e urbanísticos de São João del-Rei: embates em torno da preservação e do progresso. $224 \mathrm{f}$. Dissertação (Mestrado em Arquitetura e Urbanismo). Universidade Presbiteriana Mackenzie. São Paulo, 2013.

ARIBONI, S.; PERITO, R. Guia prático para um projeto de pesquisa exploratória, experimental, descritiva. São Paulo: Unimarco, 2004.

ATKINSON, R.; FLINT, J. Acessing hidden and hard-to-reach populations: Snowball research strategies. Social Research Update, 2001.

BAHL, M. Viagens e Roteiros Turísticos. Curitiba: Protexto, 2004.

BRAMBILLA, A.; VANZELLA, E.; BAPTISTA, M. M. Turismo cultural: Cultura, Identidades na Era Pós-Industrial. Revista Eletrônica da FAESNE, v. 1, n. 1, p. 29-40, 2014.

BOTELHO, L. L. R.; CUNHA, C. C. D. A.; MACEDO, M. Método da revisão integrativa nos estudos organizacionais. Revista eletrônica Gestão e Sociedade, Belo Horizonte, v. 5, n. 11, p. 121-136, 2011.

BRAMBATTI, L. E. Avaliação de roteiros de turismo rural: o caso da região da uva e vinho, Rio Grande do Sul, Brasil. Turismo e Sociedade, v. 12, n.3, p. 45-64, 2019.

BRASIL. Ministério do Turismo. Roteirização Turística - Módulo operacional 7. Brasília, 2007.

BRASIL. Ministério do Turismo. Mapa do Turismo, 2018. Disponível em: $<$ http://www.turismo.gov.br/\%C3\%BAltimas-not\%C3\%ADcias/11832mturpreparanovo-mapa-do-turismo-brasileiro.html>. Acesso em: 16 nov. 2018.

BRASIL. Ministério do Turismo. CADASTUR. Pesquisa de prestadores, 2020. Disponivel em: <https://cadastur.turismo.gov.br/hotsite>. Acesso em: 8 jan. 2020.

CAMARGO, L. O. Os interstícios da hospitalidade. Revista Hospitalidade, São Paulo, v. 12, n. especial, p. 42-69, 2015.

CISNE, R. D. N. C.; GASTAL, S. A produção acadêmica sobre Roteiro Turístico: um debate pela superação. In: VI SEMINÁRIO DA ASSOCIAÇÃO BRASILEIRA DE PESQUISA E PÓS-GRADUAÇÃO EM TURISMO - ANPTUR, 2009, São Paulo. 
Anais ... São Paulo: Anptur, 2009. p. 1-12. Disponível em:

$<$ https://www.anptur.org.br/anais/anais/files/6/109.pdf > . Acesso em: 11 mai 2020.

CRIATIVA, P. Caminhos do frio Rota Cultural, 2018. Disponível em:

$<$ http://www.paraibacriativa.com.br/artista/caminhos-do-frio-rota-cultural/>. Acesso em: 7 nov. 2018.

COLAÇO, T. L.; SPAREMBERGER, R. F. L. Sociedade da informação: comunidades tradicionais, identidade cultural e inclusão tecnológica. Revista de Direito Econômico e Socioambiental, v. 1, n. 1, p. 207-230, 2010.

DANTAS, N. G.; MELO, R. S. Análise da metodologia de hierarquização de atrativos turísticos como instrumento para elaboração de roteiros turísticos no município de Itabaiana (PB). Caderno Virtual de Turismo, v. 11, p. 147-163, 2011.

FUNDAÇÃO CASA DE JOSÉ AMÉRICO (FCJA), Cidade de Areia, 2018.

Disponivel em: <https://fcja.pb.gov.br/cidade-de-areia-pb>. Acesso em:16 nov. 2019.

FORNÉ, F. F.; JIMÉNEZ, C. N. La Experiencia Turística y su Crítica Intercultural. Turismo em Análise, v. 26, n. 4, p. 843-858, 2015.

GONÇALVES, L. M.; RIBEIRO, R. M. Rota e Roteiro: desafios para uma nova conceituação. Caderno de Estudos e Pesquisa do Turismo, v. 5, n. 7, p. 4-18, 2016.

INSTITUTO BRASILEIRO DE GEOGRAFIA E ESTATÍSTICA (IBGE). Areia, 2018. Disponível em: $<$ https://cidades.ibge.gov.br/brasil/pb/areia/panorama $>$. Acesso em:16 nov 2018.

INSTITUTO DO PATRIMÔNIO HISTÓRICO E ARTÍSTICO NACIONAL (IPHAN). O Iphan na Paraíba, 2020. Disponível em:

$<$ http://portal.iphan.gov.br/pagina/detalhes/347/>. Acesso em: 3 mar. 2020.

KOTLER, P.; KELLER, K. Administração de Marketing. 14. ed. São Paulo: Pearson, 2012.

LAS CASAS, A. L. Marketing de nichos e segmentos. In: LAS CASAS, A. L. Marketing de Nichos. São Paulo: Atla, 2015.

LEEUW, E. D. D.; DILLMAN, D. A.; HOX, J. J. Mixed mode surveys: When and why. In: LEEUW, E. D. D.; HOX, J. J.; DILLMAN, D. A. International Handbook of Survey Methodology. v.1, n.1, p. 299-316, 2007.

LWANGA, S. K.; LEMESHOW, S. Sample Size Determination in Health Studies: A practical Manual. WHO: Geneva, 1991.

MALHOTRA, N. K. Pesquisa de Marketing. 6. ed. Porto Alegre: Bookman, 2011.

MARCONI, M. D.; LAKATOS, E. M. Metodologia do trabalho científico. 8 ed. São Paulo: Atlas, 2017. 
MARTINS, E. C. Cultura e poder 2 ed. São Paulo: Saraiva, 2007.

MOLETTA, V. F. Turismo Cultural. Porto Alegre: SEBRAE, 1998.

PARAÍBA, A. L. D. Assembléia Legislativa da Paraíba: Arthur recebe título de Cidadania Areiense. Paraíba, 2008. Disponivel em:

$<$ http://www.al.pb.leg.br/1862/arthur-recebe-ttulo-de-cidadania-areiense.html $>$. Acesso em: 11 mai 2020.

PEZZI, E.; SANTOS, R. J. D. A experiência turística e o turismo de experiência: aproximações entre a antropologia e o marketing. In: VII SEMINÁRIO DE PESQUISA EM TURISMO DO MERCOSUL, 2012, Caxias do Sul. Anais ... Caxias do Sul: UCS, 2012. p. 1-13. Disponível em:

$<$ https://www.ucs.br/ucs/eventos/seminarios_semintur/semin_tur_7/arquivos/02/09_Pez zi_Santos.pdf $>$. Acesso em: 11 mai. 2020.

PRODANOV, C.C.; FREITAS, E. C.Metodologia do trabalho científico: métodos e técnicas da pesquisa e do trabalho acadêmico 2 ed. Novo Hamburgo: Universidade Feevale, 2013.

RIBEIRO, G. C.; MONDO, T. S. Pluriatividade Rural: a percepção de agricultura de Lages, Santa Catarina, sobre a oferta de hospedagem. Turismo e Sociedade, v. 12, n. 2, p. 23-44, 2019.

RODGERS, B. L.; KNAFL, K. A. Concept Development in Nursing. Philadelphia: Saunders, 2000.

RUSSO, A. A União, 2017. 12 a Edição da rota Cultural Caminhos do Frio. Disponivel em: $<$ https://auniao.pb.gov.br/noticias/caderno_paraiba/pbtur-lanca-12aedicao-da-rota-cultural-caminhos-do-frio>. Acesso em: 10 mai 2020.

SMITH, M. Issues in Cultural TourismStudies. New York: Routledge, 2003.

TAVARES, A. D. M. City-Tour. São Paulo: Aleph, 2002.

TIMOTHY, D.; BOYD, S. Tourism in the 21st Century: Valued Traditions and New Perspectives. Journal of Heritage Tourism, v. 1, n. 1, p.1-16, 2006.

VIANA, L. H. V. A ideologia na produção do espaço: os megaeventos como agentes difusores da ideologia (neo)liberal. Cadernos Metrópole, v. 21, n. 44, p. 79-97, 2019.

VOSGERAU, D. S. R.; ROMANOWSKI, J. P. Estudos de revisão: implicações conceituais e metodológicos. Revista Diálogo Educacional, v. 14, n. 41, p. 165-189, 2014. 